\title{
Successional trends in standing dead biomass in Mediterranean Basin species
}

\author{
Baeza, M.J., Santana, V.M., Pausas, J.G. \& Vallejo, V.R.
}

Baeza, M.J. (Corresponding author; jaime.baeza@ua.es), Santana, V.M. (vm.santana@ua.es) \& Vallejo, V.R. (vvallejo@ub.edu): CEAM (Centro de Estudios Ambientales del Mediterráneo), C/ Charles R. Darwin, 14, 46980. Paterna, Valencia. Spain. http://www.ceam.es Baeza, M.J.: Universidad de Alicante, Ap. 99, E-03080, Alicante, Spain; Pausas, J.G. (juli.g.pausas@uv.es): Centro de Investigaciones sobre Desertificación (CIDE, CSICUV), IVIA Campus, 46113 Montcada, Valencia, Spain.

\begin{abstract}
Question: Landscape models of fire occurrence in ecosystems assume that the time since the last fire determines vegetation flammability by enabling the accumulation of dead biomass. In this study we ask if Mediterranean Basin shrublands respond to these models or, on the contrary, if initial successional stages in these ecosystems could be more flammable than later stages.

Location: Mediterranean shrubland in the Valencia Region, eastern Spain.

Methods: Using different stages of vegetation development $(5,9,14$ and 26 years since the last fire), we first study the structural composition of the above-ground biomass in 375 individuals of nine woody species. Then, we measure how the standing dead biomass varies during succession, taking into account the surface cover of each species and the quantity of total dead biomass accumulated in different successional stages (3, 9, 14 and 26 years since the last fire).

Results: The largest amount of standing dead biomass at the plant community level is observed in the middle stages of the succession. Early successional species, such as Cistus spp., Ulex parviflorus and Pinus halepensis, have a higher percentage of standing dead biomass at earlier stages in the succession than species typical of later successional stages, like Juniperus oxycedrus, Quercus coccifera and Quercus ilex.

Conclusions: These results suggest that monotonic increase in fire hazard with increasing stand age is not necessarily the rule in Mediterranean Basin shrublands, since early successional species may accumulate large amounts of standing dead biomass and thus promote fire at early successional stages.
\end{abstract}

Keywords: Early and late species, flammability, retaining dead fuel, successional stages, species replacement, woody species. 


\section{Introduction}

Ecosystem flammability is an emergent property of plant communities (Troumbis \& Trabaud 1989; Lavorel \& Garnier 2002; Schwilk 2003) that involves interacting biotic and abiotic processes. In the strict sense, flammability indicates how easily a plant will ignite (ignitability) and how quickly the flames will spread (combustibility) (Cornelissen et al. 2003). Physical and chemical properties of plant tissue, such as water content (branches, twigs and leaves), fuel particle density and size, volatile oils, resins and mineral content, are mainly related to the ignition phase. Spatial distribution determined by fuel architecture and structure mainly affects combustibility and are related to fire spread. Among the most important plant properties involved in flammability is the retention of standing dead biomass (Schwilk \& Ackerly 2001). This is relevant because high load of standing dead biomass with low water content is critical during dry season and enhances plant flammability and this property can vary with changes in the plant community over time (Whelan 1995; Bond \& van Wilgen 1996; Baeza et al. 2006).

Landscape models of fire occurrence in ecosystems assume that the time since the last fire determines vegetation flammability (Rothermel \& Philpot 1973; Keane et al. 2004). This supposes that continuing fuel accumulation and an increased fraction of dead material will result in an increasing probability of fire (Bond \& van Wilgen 1996; Bond \& Keeley 2005). The fire interval distribution, believed to describe how the fire risk changes over time, is estimated from stand-age maps based on the Weibull time-since-fire model (Johnson \& Gutsell, 1994) where there would be a lower probability of burning in younger fuels and most fires would occur in mid-aged to old fuels. However, some studies have questioned this pattern of burning probability determined simply by fuel accumulation over time. Under extreme fire weather conditions all age classes can easily burn (Moritz 2003; Turner et al. 2003; Moritz et al. 2004). In the Mediterranean Basin, under less extreme weather conditions, small fires seem to be particularly selective and show a strong preference for early successional shrublands (Díaz-Delgado et al. 2002; Nunes et al. 2005; Moreira et al. 2009). In addition, recent studies in California shrublands have suggested that fire distribution frequencies do not respond to as predicted by simple models of age-dependent flammability because seral stage chaparral is dominated by herbaceous perennials and short-lived species which produce sufficient dead fuel to spread fire under relatively low winds (Keeley \& Zedler 2009). Thus, flammability does do not seem to be always monotonically related to the age of the vegetation (Moritz et al. 2004; Keeley \& Zedler 2009).

Fire modifies environmental conditions drastically and generates changes in resource availability all along the post-fire successional gradient. In succession less competitive species are replaced by more competitive ones through time (Huston \& Smith 1987), and these changes in species composition along the successional gradient could likewise generate changes in vegetation flammability depending on the flammability traits of the co-occurring species in the community. In addition, it is worth noting that flammability of species has been suggested as a niche construction trait since the retention of dead branches in the canopy contributes greatly to determine plant regeneration after fire (Schwilk 2003), and probably one relevant trait linking flammability and vegetation successional dynamics could be standing dead biomass. Nevertheless, recent conceptual frameworks indicate that traits associated with fire response show few correlations with traits determining ecosystem flammability (Bond \& Midgley 1995; Lavorel \& Garnier 2002; Saura-Mas et al. 2010).

In Mediterranean ecosystems the successional trajectory after fire involves a parallel increase in fuel amounts and changes in species composition (Cramer et al. 2008), where a predictable directional replacement of flammable (pine forest) to non-flammable (hardwood forest) vegetation has been observed after long intervals without fire (Bond \& van Wilgen 1996; Whelan 1995). Analyses of functional traits have revealed correlation between occurrence of various traits and successional status of species (Rees et al. 2001; Platt \& Connell 2003). The tendency to accumulate standing dead biomass through rapid growth may be such a trait, and could, if 
correlated with successional status, play a significant role in driving fire recurrence by influencing flammability. Consequently, in the present study we assess the hypothesis that species present in the first stages of plant succession rapidly accumulate dead biomass (i.e., highly flammable fuel), while species occurring at more mature successional stages accumulate fuel at lower rates (i.e., thick fuel with low flammability). To test this hypothesis, we have assessed the properties and amounts of accumulated dead fuel since the last fire event for nine of the most dominant species of Mediterranean Basin ecosystems. Then, we used these values to explore fire susceptibility from early to late successional stages in Mediterranean gorse shrubland. In the context of post-fire vegetation succession this kind of information is scarce and this work could contribute in the assessment of the role of standing dead biomass in driving the probability of fire ignition.

\section{Methods}

\section{Study site and experimental design}

This study was conducted in the eastern Iberian Peninsula (Valencia region) and followed two steps to characterise dead fuel dynamics through time: 1) the assessment of biomass structural variables by species and by different fuel fractions (live, dead and diameter class of fuel); 2) the assessment of changes in the amount of standing dead biomass at the community level as a consequence of successional processess. Each step was performed on two different sites separated by about $40 \mathrm{~km}$, one in the interior of the province of Valencia (hereafter Ayora site: $39^{\circ} 05^{\prime}-40^{\circ} 5^{\prime} \mathrm{N}, 0^{\circ} 51^{\prime}-1^{\circ} 59^{\prime} \mathrm{W}$ ) and the other in the north of Alicante Province (hereafter Alicante-North sites: $38^{\circ} 35^{\prime}-38^{\circ} 43^{\prime} \mathrm{N}$, $\left.0^{\circ} 9^{\prime}-0^{\circ} 40^{\prime} \mathrm{W}\right)$. These sites fall into the same environmental region characterised by a sub-dry mesoMediterranean climate (Thornwaite 1948) with mean temperatures between $13-17^{\circ} \mathrm{C}$ and an annual mean rainfall between 400-700 $\mathrm{mm}$. Leptosols, stony soils formed on limestone and dolomite, dominate in the uplands of the study area while Regosols, less stony soils formed on marl, dominate in the lower colluvial areas. The landscape is occupied mainly by shrublands dominated by Rosmarinus officinalis, Ulex parviflorus, several Cistus species and Quercus coccifera. Forests are absent but there are small patches of trees (e.g., Quercus ilex and Pinus halepensis).

\section{Sampling of species-specific structural variables}

Using fire history records from the Forest Service of the Regional Government of Valencia, we selected four areas on the Ayora site which had sustained fires in the summers of 1979, 1991, 1996 and 2000 (30.000, 5.000, 600 and 50 ha respectively), thus providing us with a stand-age chronosequence of $26,14,9$ and 5 years since the last fire.

On each site we measured biomass structural variables by species and by fuel fractions (i.e., live and dead fuel and different diameter classes of fuel). We selected nine woody species representing 85-90\% of the vegetation cover on the Ayora site (Baeza et al. 2007). These species were: Cistus clusii, Cistus albidus, Erica multiflora, Juniperus oxycedrus, Pinus halepensis, Quercus coccifera, Quercus ilex, Rosmarinus officinalis and Ulex parviflorus (nomenclature follows De Bolòs et al. 1993), which include shrubs and trees, early and late successional species, and different regeneration strategies after fire (seeder and resprouter) (Table 1). In each fire area we sampled a plot of 2-3 ha, where 10-12 individuals of each species were randomly selected (a total of 340 individuals) and harvested during the autumn-winter of 2004 and 2005. Individuals that were isolated, dead, broken or growing in especially favourable locations were avoided. In addition, we included fuel structure data from 35 individuals of $U$. parviflorus (young, mature and senescent individuals) taken from a previous study (Baeza et al. 2006). For resprouter species we considered the ramet, i.e., the unsuppressed mid-developed shoot that sprouts directly from the burnt stump. In order to confirm the age of our plants we counted growth rings in J. oxycedrus and P. halepensis (as representative of resprouter and seeder species, respectively) for all individuals and plots. We also 
counted growth rings in U. parviflorus, R. officinalis and C. albidus in the 26-year-old stand to confirm the life span of these individuals.

For each plant and before harvesting we measured structural variables including basal stem diameter, height and maximum and perpendicular crown diameters. The dead material collected consisted mainly of twigs situated in the lower part of the individual canopy. For each individual plant, biomass was separated into live and dead fractions, and then grouped by diameter class $<0.6$ $\mathrm{cm}$ (twigs), $0.6-2.5 \mathrm{~cm}$ (thin branches), $2.51-7.5 \mathrm{~cm}$ (thick branches) and $>7.5 \mathrm{~cm}$ (trunk) (Brown, 1970). Leaves (or phylloides for U. parviflorus) were included in the live thin fraction $(<0.6 \mathrm{~cm})$; tree trunks $(>7.5 \mathrm{~cm})$ were not considered to contribute to the fuel consumable by fire. The separated material was then dried to a constant weight in a forced-air oven at $80^{\circ} \mathrm{C}$.

Testing for successional trends in the standing dead biomass

To test the role of successional processes in shifting the amount of standing dead biomass at the community level, we selected areas on the Alicante-North site which had been burned in the summers of 1979, 1984 and 1991. The wildfire of 1979 was sampled in 2005. The area burned in 1984 was sampled in both 1994 and 1998 and the last fire was sampled in 1994. These selected areas represented shrublands at different post-fire stages of development $(3,9,14$ and 26 years since the last fire). Each of the shrubland age groups included three different replicated fires, with the exception of the 26-year-old shrubland where we used 3 plots in the same fire. All the different wildfires on the Alicante-North site had been used for previous studies (see Baeza et al. 2006, 2007 for more details).

At each fire, we installed 5 permanent transects of $5 \mathrm{~m}$ in length, parallel to each other and separated by $2 \mathrm{~m}$. Vegetation cover was recorded by the point-intersect method using a $3 \mathrm{~mm}$ diameter rod (Greig-Smith 1983) and taking a measurement every $10 \mathrm{~cm}$. To calculate the specific cover, we recorded the presence of the different species at each point, thus obtaining the specific plant frequency. To obtain information on the amount of standing dead biomass at the community level, we randomly selected six-eight $(1 \mathrm{x} 1 \mathrm{~m})$ subplots where we extracted all aboveground biomass. Then, the fraction corresponding to dead fuel was separated and weighed in the laboratory. A more detailed description of the methods applied can be found in Baeza et al. $(2006,2007)$.

\section{Data analysis}

Regression analysis was used to determine the relationship between ring number and stand age (years since last fire). Species differences in total dead biomass and specific cover (\%) between stand ages and standing dead biomass accumulated along succession were tested with analysis of variance (ANOVA). The total amount of dead biomass retained by individuals in the oldest successional stage (26 years) was compared using analysis of variance (ANOVA). To homogenise the variance, we applied an angular transformation for proportions and a natural logarithm for total dead biomass. Their evaluation was performed with the Levene test. For post hoc comparisons of means we used Tukey's multiple range test. The SPSS 15.0 statistical package (SPSS Inc. Chicago, IL, USA) was utilized for statistical analyses.

\section{Results}

\section{Species-specific accumulation of dead fuel}

There was a strong 1:1 relation between age based on growth rings (observed age) and the time since last fire (stand age) (Fig. 1). With the exception of C. albidus (21.4 \pm 1.2 years) which presented ring identification problems due to wood rot in the center of the stem, all the species showed an average deviation of around one year between time since the last fire and observed age. 
Most of the species showed a trend towards accumulating dead biomass as percentage of total with time-since-the-last-fire (Fig. 2). Only $J$. oxycedrus showed no significant increase in the percentage of total dead biomass accumulated with the time since fire (d.f. $=3 ; \mathrm{F}=1.51 ; p=0.228$ ) and marginally significant for $C$. albidus $(\mathrm{d} . \mathrm{f} .=3 ; \mathrm{F}=2.461 ; p=0.078)$. U. parviflorus presented the most distinctive pattern of all the species studied (Fig. 2). This species showed significant differences in the percentage of total dead biomass with time since last fire (d.f. $=3 ; \mathrm{F}=98.71$; $\mathrm{p}<0.001)$, registering the highest values at 9 years of age $(56.8 \%)$ and significantly lower values at 14 and 26 years of age (43.6 and 39.9\% respectively). Some species, including C. clusii, P. halepensis and $R$. officinalis, also showed significant differences in the percentage of total dead fuel retained between stand ages (d.f. $=3 ; \mathrm{F}=27.22, p<0.0001$; d.f. $=3 ; \mathrm{F}=31.06, p<0.0001$ and d.f. $=3$; $\mathrm{F}=16.54, p<0.0001$ respectively), although the post-hoc Tukey test indicated that the differences were only significant at the age of 26 , the age at which the highest values were obtained: $29.7,13.4$ and $8.1 \%$ for $C$. clusii, $P$. halepensis and $R$. officinalis respectively. E. multiflora was the only species showing a significant increase at each of the different times since the last fire (d.f. $=3$; $\mathrm{F}=59.58, p<0.001$ ), with a maximum value of $17.4 \%$ at 26 years of age. Significant differences with stand age were observed in both $Q$. ilex and $Q$. coccifera (d.f. $=3 ; \mathrm{F}=3.16, p=0.035 ;$ d.f. $=3 ; \mathrm{F}=17.30$, $p<0.0001$ ), with relatively low dead-fuel values that oscillated between 4.4 and $8.7 \%$ at 9 and 26 years-of-age respectively in $Q$. coccifera and between 0.54 and $6.00 \%$ at 5 and 9 years-of-age respectively in $Q$. ilex.

The amount of dead biomass retained in the canopy at the oldest age (26 years old showed significant differences (d.f. $=8 ; \mathrm{F}=32.8, p<0.0001$ ) among many of the species studied (Fig. 3). Variation among species was large; where trees like $P$. halepensis accumulated values up to $7000 \mathrm{~g}$ individual, other macrophanerophytes like $Q$. ilex barely reached $300 \mathrm{~g}$ per individual and $J$. oxycedrus, barely $100 \mathrm{~g}$ per individual. Among shrub species $U$. parviflorus retained the most dead biomass, followed by E. multiflora, while $R$. officinalis, $Q$. coccifera and $C$. clusii presented lower amounts (Fig. 3).

\section{Successional trends of the dead fuel}

Some species (J. oxycedrus, $Q$. coccifera and $P$. halepensis) did not show significant differences (d.f. $=3 ; \mathrm{F}=0.9, p=0.456$; d.f. $=3 ; \mathrm{F}=0.2, p=0.881 ;$ d.f. $=3 ; \mathrm{F}=0.78, p=0.535$ ) in the percentage of cover at each of the different times since the last fire (Fig. 4). Other species showed two distinct patterns. For $U$. parviflorus and $C$. albidus the highest values of cover were observed at intermediate stages of succesion (d.f. $=3 ; \mathrm{F}=25.1 ; p<0.0001 ;$ d.f. $=3 ; \mathrm{F}=8.22 ; p=0.008$ ), whilst for $E$. multiflora and $R$. officinalis the highest values were observed in later successional stages (Fig. 4) (d.f. $=3 ; \mathrm{F}=11.8 ; p=0.003 ;$ d.f. $=3 ; \mathrm{F}=12.07 ; p=0.002$ ).

At community level, standing dead biomass accumulation showed significant differences (d.f.=3; $\mathrm{F}=101.5, p<0.0001$ ) between the different successional stages of Mediterranean gorse shrublands (Fig. 5). The lowest values $\left(25.5 \mathrm{~g} / \mathrm{m}^{2}\right.$ of standing dead biomass) were found at the earliest successional stages (3-year-old plots). In contrast, the highest values were observed on the intermediate-aged plots, with 1580.3 and $1274.1\left(\mathrm{~g} / \mathrm{m}^{2}\right)$ at 9 and 14 years of age, respectively. The oldest stands showed a striking decrease in standing dead biomass, to $731.9\left(\mathrm{~g} / \mathrm{m}^{2}\right)$ at 26 years of age (Fig. 5).

\section{Discussion}

The amount of standing dead biomass in the canopy and rates of dead-fuel accumulation varied with the time since the last fire in patterns that varied among species. For Mediterranean gorse shrubland, these different trends in standing dead biomass for the species studied are reflected in the fact that, the highest fire susceptibility was observed in the intermediate successional stages, while the oldest successional stages showed a marked decrease in the amount of standing dead biomass 
and, thus, in the susceptibility to fire. Shrubs and dwarf shrub species with a strategy of rapid colonization after disturbances, such as C. clusii, C. albidus, and U. parviflorus, retained a high percentage of standing dead biomass, a pattern similar to the one shown by the early successional trees $P$. halepensis. In contrast, the competitive species typical of later successional stages, e.g., $Q$. coccifera, $J$. oxycedrus and especially $Q$. ilex, retained low amounts of dead biomass in the lower strata of the canopy. These results, at least in our study area suggest that changes in the temporal and spatial patterns of plant community composition could be involved in ecosystem flammability. These results are consistent with the positive feedback between shrublands and fire in communities in early stages of succession described in several studies of the Mediterranean Basin (Nunes et al. 2005; Salvador et al. 2005). However, our results show that continuously increasing fire hazard with increasing stand age is not necessarily the rule in Mediterranean Basin shrublands. For instance, $C$. albidus, can present up to $20 \%$ standing dead biomass as early as the first stand age (5 years), while other species, such as Ulex parviflorus, can register as much as $57 \%$ standing dead biomass at 9 years of age. Studies on fire frequency distributions in chaparral (Keeley et al. 1999; Moritz et al. 2004) concluded that the fire interval did not exhibit a strong fuel-age effect because weather conditions were more related to fire behaviour mechanisms (Bessie \& Jonhson 1995). Nevertheless, there is still insufficient knowledge on how biomass accumulations and flammability can vary with age and within species, and it has been suggested that different communities may have a greater or a lower susceptibility to fire depending on the species composition (Bond \& van Wilgen 1996, Mermoz et al. 2005, Syphard et al. 2006; Scarff \& Westoby 2006; Saura-Mas et al. 2010). The different temporal patterns of standing dead biomass shown in the 9 species studied here suggest the variation in species biomass accumulation curves can result in complex changes in community flammability with time. This would be in consonance with the theoretical fire-interval distribution suggested for Australian forests where there is a variety of fire interval distributions in nature based on ecosystem dynamics and biomass composition (McCarthy et al. 1999; McCarthy et al. 2001).

If dead branch retention is correlated with plant flammability (Schwilk 2003; Bond \& Keeley 2005) and the dead to live biomass ratio varies with age, then changes in flammability could be affected by the successional dynamics process because species composition varies as resource availability changes along the successional gradient (Tilman 1985; Huston \& Smith 1987; Platt \& Connell 2003). Our results show that in the more advanced developmental stages, C. albidus, $C$. clusii, E. multiflora and $U$. parviflorus contribute the most community dead-twig fraction while $Q$. ilex, J. oxycedrus and, to a lesser degree, $Q$. coccifera and $P$. halepensis provided a small contribution to dead-twig fraction at the same stages. Previous research carried out at the Ayora site (Baeza et al. 2007) found that in the early successional stages the most abundant species were C. albidus and C. clusii; in the medium-term, U. parviflorus was the most abundant; from 20-25 years after the fire, these species were replaced by $R$. officinalis. Although longevity data are scarce, this successional trajectory could indicate that life span is highly responsible for these patterns (Lloret 2004). Species lifespan, then, can have a role in influencing fire behaviour because dead individuals in the successional sequence increase dead biomass and enhance ecosystem flammability. Therefore, the replacement of early species by later species with scant amounts of accumulated dead biomass could reduce flammability in the more advanced stages of the succession (Bond \& Midgley 1995; Bond \& van Wilgen 1996). It has been widely suggested that scenarios with high fire recurrence mantain early successional communities (Pausas 1999; Walker \& Reddell 2007). These new vegetation types with greater susceptibility to fire result from the conversion of forest to shrubland (Mermoz et al. 2005; Donato et al. 2009), chaparral to coastal sage scrub (Syphard et al. 2006; Keeley et al. 2005), heath-shrubland to open herb-sedgeland (Bradstock et al. 1997) and heathland to dwarf shrublands (Ojeda et al. 1996; Lloret 2004; Baeza et al. 2007), while longer fire intervals may result in a replacement of fire-prone species with less flammable species (Odion et al. 2004; Bond et al. 2005). 
Some studies have correlated flammability traits with reproductive traits relating to fire response in plants (Bond \& Midgley 1995; Schwilk \& Ackerly 2001; Bond \& Keeley 2005; SauraMas et al. 2010; Ojeda et al. 2010). Fire regimes are considered, at least in Mediterranean Basin, to have an important influence on floristic composition, and more frequent fires have been observed to lead to increases in obligate seeders (Pausas 1999, 2003; Lloret 2004; Lloret et al. 2005; Baeza et al. 2007; Santana et al. 2010). Our study suggests that flammability traits (retention of standing dead biomass) could be related to successional processes dependent on resource availability (e.g. light) throughout the successional trajectory. In the early successional stages the typical dominant species are short-lived, fast-growing, shade-intolerant pioneers that reproduce from seed. In our study these species are shrubs and dwarf shrubs, or trees dependent on the fire regime, like Cistus spp, $U$. parviflous or $P$. halepensis, that show decreased survival when vegetation canopy closes.

There is little information in the literature on the ecological significance of retaining standing dead biomass. However, the fact that Mediterranean Basin species with highest proportion of dead fuel (Fig. 2) are early-successional seeder species with germination strongly stimulated by the heat of the fires (Moreira et al. 2010) is consistent with the idea that flammability as a trait might be positively selected through contribution to increased fire frequency or intensity ensuring massive regeneration post-fire. Indeed, recent studies suggested that seeder species of the Mediterranean Basin tend to have higher dead-to-live fuel ratio and that they burst into flame at lower temperatures than non-seeders (Saura-Mas et al. 2010).

\section{Acknowledgements}

We thank J. Scheiding for the English translation of the text and Ana Sevilla for her collaboration in laboratory and field sampling. Comments from Dr. K. Woods and two anonymous referees have greatly improved the quality of the manuscript. This research has been financed by the following Spanish National projects: GRACCIE (Consolider-Ingenio 2010, CSD2007-00067), FIREMED (AGL2008-04522/FOR) and VIRRA (CGL2009-12048/BOS). CEAM is supported by the Generalitat Valenciana and the Fundación Bancaja. CIDE is supported by CSIC, Generalitat Valenciana and Universitat de Valencia.

\section{References}

Baeza, M.J., Raventós, J., Escarré, A. \& Vallejo, V.R. 2006. Fire risk and vegetation structural dynamics in Mediterranean shrubland. Plant Ecology, 187, 189-201.

Baeza M.J. \& Vallejo, V.R. 2007. Vegetation recovery after fuel management in Mediterranean shrublands. Applied Vegetation Science, 11, 151-158.

Baeza M.J., Valdecantos, A., Alloza, J.A. \& Vallejo, V.R. 2007. Human disturbance and environmental factors as drivers of long-term post-fire regeneration patterns in Mediterranean forest. Journal of Vegetation Science, 18, 243-252.

Bessie, W.C. \& Johnson, E.A. 1995. The relative importance of fuels and weather on fire behavior in subalpine forests. Ecology, 76, 747-762.

Bond, W.J. \& Midgley, J.J. 1995. Kill thy neighbour: an individualistic argument for the evolution of flammability. Oikos, 73, 79-85.

Bond, W.J. \& van Wilgen, B. W. 1996. Fire and plants. Chapman \& Hall. London.

Bond, W.J. \& Keeley, J.E. 2005. Fire as a global 'herbivore': the ecology and evolution of flammable ecosystems. Trends in Ecology and Evolution, 20, 387-394.

Bond, W.J., Woodward, F.I. \& Midgley, G.F. 2005. The global distribution of ecosystems in a world without fire. New Phytologist, 165, 525-538.

Bradstock, R.A., Tozer, M.G. \& Keith, D.A. 1997. Effects of high frequency fire on floristic composition and abundance in a fire-prone heathland near Sydney. Australian Journal of Botany, 45, 641-655. 
Brown, J.K. 1970. Ratios of surface area to volume for common fine fuels. Forest Science, 16, 101105.

Cornelissen, J.H., Lavorel, S., Garnier, E., Díaz, S., Buchmann, N. et al. 2003. A handbook of protocols for standardised and easy measurement of plant functional traits worldwide. Australian Journal of Botany, 51, 335-380.

Cramer, A., Hobbs, R.J. \& Standish, R.J. 2008. What's new about old fields? Land abandonment and ecosystem assembly. Trends in Ecology and Evolution, 23, 104-112.

De Bolòs, O., Vigo, J., Masalles, R.M. \& Ninot, J.M. 1993. Flora Manual dels Països Catalans, 2nd. ed. Pòrtic, Barcelona.

Díaz-Delgado, R., Lloret, F., Pons, X. \& Terradas, J. 2002. Satellite evidence of decreasing resilience in Mediterranean plant communities after recurrent wildfire. Ecology, 83, 22932303.

Donato, D.C., Fontaine, J.B., Robinson, W.D., Kauffman, J.B. \& Law, B.E. 2009. Vegetation response to a short interval between high-severity wildfires in a mixed-evergreen forest. Journal of Ecology, 97, 142-154.

Greig-Smith, P. 1983. Quantitative plant ecology. 3 rd ed. Blackwell, Oxford, UK.

Huston, M. \& Smith, T. 1987. Plant succession: life history and competition. American Naturalist, 130, 168-198.

Johnson, E.A. \& Gutsell, S.L. 1994. Fire frequency models, methods and interpretations. Advances in Ecological Research, 25, 239-287.

Keane, R.E., Cary, G.J., Davies, I.D. et al. 2004. A classification of landscape fire succession models: spatial simulations of fire and vegetation dynamics. Ecological Modelling, 179, 327.

Keeley, J.E. \& Zedler, P.H. 2009. Large, high-intensity fire events in southern California shrublands: debunking the fine-grain age path model. Ecological Applications, 19, 69-94.

Keeley, J.E., Fotheringham, C.J. \& Morais, M. 1999. Reexamining fire suppression impacts on brushland fire regimes. Science, 284, 1829-1832.

Keeley, J.E., Fotheringham, C.J. \& Baer-Keeley, M. 2005. Determinants of postfire recovery and succession in Mediterranean-climate shrublands of California. Ecological Applications, 15, 1515-1534.

Lavorel, S. \& Garnier, E. 2002. Predicting changes in community composition and ecosystem functioning from plant traits: revisiting the Holy Grail. Functional Ecology, 16, 545-556.

Lloret, F. 2004. Régimen de incendios y regeneración. In: Valladares, F. (ed.) Ecología del bosque mediterráneo en un mundo cambiante, pp. 249-277. Ministerio de Medio Ambiente. EGRAF, S.A. Madrid.

Lloret, F., Estevan, H., Vayreda, J. \& Terradas. J. 2005. Fire regenerative syndromes of forest woody species across fire and climatic gradients. Oecologia, 146, 461-468.

McCarthy, M.A., Gill, A.M. \& Lindenmayer, D.B. 1999. Fire regimes in mountain ash forest: evidence from forest age structure, extinction models and wildlife habitat. Forest Ecology and Management, 124, 193-203.

McCarthy M.A., Malcolm G. \& Bradstock, R.A. 2001. Theoretical fire-interval distributions. International Journal of Wildland Fire, 10, 73-77.

Mermoz, M., Kitzberger, T. \& Veblen, T.T. 2005. Landscape influences on occurrence and spread of wildfires in Patagonian forests and shrublands. Ecology, 86, 2705-2715.

Moreira, B., Tormo, J., Estrelles, E. \& Pausas, J. G. 2010. Disentangling the role of heat and smoke as germination cues in Mediterranean Basin flora. Annals of Botany, 105 (4), 627-635.

Moreira F., Vaz P., Catry F. \& Silva J.S. 2009. Regional variations in wildfire susceptibility of land-cover types in Portugal: implications for landscape management to minimize fire hazard. International Journal of Wildland Fire, 18, 563-574.

Moritz, M.A. 2003. Spatiotemporal analysis of controls on shrubland fire regimes: age dependency and fire hazard. Ecology, 84, 351-361. 
Moritz, M.A., Keeley, J.E., Johnson E.A. \& Schaffner A.A. 2004. Testing a basic assumption of shrubland fire management: how important is fuel age? Frontiers in Ecology and Environment, 2, 67-72.

Nunes, M.C., Vasconcelos, M.J., Pereira, J.M., Dasgupta, N., Alldredge R.J. \& Rego, F.C. 2005. Land cover type and fire in Portugal: do fires burn land cover selectively? Landscape Ecology, 20, 661-673.

Odion, D.C., Frost, E.F., Strittholt, J.R., Jian, H., Dellasala, D.A. \& Moritz, M.A. 2004. Patterns of fire severity and forest conditions in the western Klamath Mountains, California. Conservation Biology, 18, 927-936.

Ojeda, F., Marañon, T. \& Arroyo, J. 1996. Post-fire regeneration of a Mediterranean heathland in Southern Spain. International Journal of Wildland Fire, 6, 191-198.

Ojeda, F., Pausas, J.G. \& Verdú, M. 2010. Soil shapes community structure through fire. Oecologia, 163, 729-735.

Paula, S., Arianoutsou, M., Kazanis, D., Tavsanoglu, Ç., Lloret, F., Buhk, C., Ojeda, F., Luna, B., Moreno, J.M., Rodrigo, A., Espelta, J.M. Palacio, S., Fernandez-Santos, B., Fernandes, P.M. \& Pausas, J.G. 2009. Fire-related traits for plant species of Mediterranean Basin. Ecology, $90,1420$.

Pausas, J.G. 1999. The response of plant functional types to changes in the fire regime in Mediterranean ecosystems. A simulation approach. Journal of Vegetation Science, 10, $717-$ 722.

Pausas, J.G. 2003. The effect of landscape pattern on Mediterranean vegetation dynamics: A modelling approach using functional types. Journal of Vegetation Science, 14, 365-374.

Platt, W.J. \& Connell, J.H. 2003. Natural disturbances and directional replacement of species. Ecological Monographs, 73, 507-522.

Rees, M., Condit, R., Crawley, M., Pacala, S. \& Tilman, D. 2001. Long-term studies of vegetation dynamics. Science, 293, 650-655.

Rothermel, R.C. \& Philpot, C.W. 1973. Predicting changes in chaparral flammability. Journal of Forestry, 71, 640-643.

Salvador, R. Lloret, F., Pons, X. \& Piñol, J. 2005. Does fire recurrence modify the probability of being burned again? A null hypothesis test from Mediterranean ecosystems in NE Spain. Ecological Modelling, 188, 461-469.

Santana, V.M., Baeza, M.J., Marrs, R.H. \& Vallejo, V.R. 2010. Old-field secondary succession in SE Spain: may fire divert it? Plant Ecology, 211, 337-349.

Saura-Mas, S., Paula, S., Pausas, J.G. \& Lloret, F. 2010. Fuel loading and flammability in the Mediterranean Basin woody species with different post-fire regenerative strategies. International Journal of Wildland Fire, 19, 783-794.

Scarff, F.R. \& Westoby, M. 2006. Leaf litter flammability in some semi-arid Australian woodlands. Functional Ecology, 20, 745-752.

Schwilk, D.D. 2003. Flammability is a niche construction trait: canopy architecture affects fire intensity. American Naturalist, 162, 725-733.

Schwilk, D.W. \& Ackerly, D.D. 2001. Flammability and serotiny as strategies: correlated evolution in pines. Oikos, 94, 326-336.

Syphard, A.D., Flanklin, J. \& Keeley, J.E. 2006. Simulating the effects of frequent fire on southern California coastal shrublands. Ecological Applications, 16, 1744-1756.

Thornwaite, C.W. 1948. An approach toward a rational classification of climate. Geographical Review, 38, 55-94.

Tilman, D. 1985. The resource-ratio hypothesis of plant succesion. American Naturalist, 125, 827852.

Troumbis, A. \& Trabaud, L. 1989. Some questions about flammability in fire ecology. Acta Oecologica, 10, 167-175: 
Turner, M.G., Romme, W.H. \& Tinker D.B. 2003. Surprises and lessons from the 1988 Yellowstone fires. Frontiers in Ecology and Environment, 1, 351-358.

Walker, J. \& Reddell, P. 2007. Retrogressive succession and restoration on old landscapes. In: Walker, L.R., Walker, J. \& Hobbs, R.J. (eds.) Linking restoration and ecological succession. pp. 69-89. Springer, New York.

Whelan, R.J. 1995. The Ecology of Fire. Cambridge University Press. New York.

\section{Tables}

Table 1.

\begin{tabular}{|c|c|c|c|c|c|}
\hline & Life form & $\begin{array}{l}\text { Persistence strategie } \\
\text { after fire }\end{array}$ & $\begin{array}{c}\text { Life span } \\
\text { (years) }\end{array}$ & Dispersal & $\begin{array}{l}\text { Maturation time } \\
\text { (years) }\end{array}$ \\
\hline C. albidus & Dwarf shrub & Seeder & Short (10-15) & Myrmecochory & Short (2) \\
\hline E. multiflora & Shrub & Resprouter & Medium $(30-40)$ & Anemochory & Short (3-4) \\
\hline J. oxycedrus & Large shrub & Resprouter & Long $(>50)$ & Endo-zoochory & Medium (5-10) \\
\hline P. halepensis & Tree & Seeder & Very long $(>200)$ & Anemochory & Long (10-15) \\
\hline Q. coccifera & Shrub & Resprouter & Long $(>50)$ & Endo-zoochory & Medium $(5-10)$ \\
\hline Q. ilex & Tree & Resprouter & Very long $(>200)$ & Endo-zoochory & Long $(15-20)$ \\
\hline R. officinalis & Shrub & Seeder & Medium $(30-40)$ & Myrmecochory & Short (2-3) \\
\hline U. parviflorus & Shrub & Seeder & Short (15-20) & Myrmecochory & Short (2-3) \\
\hline
\end{tabular}

\section{FIGURES}

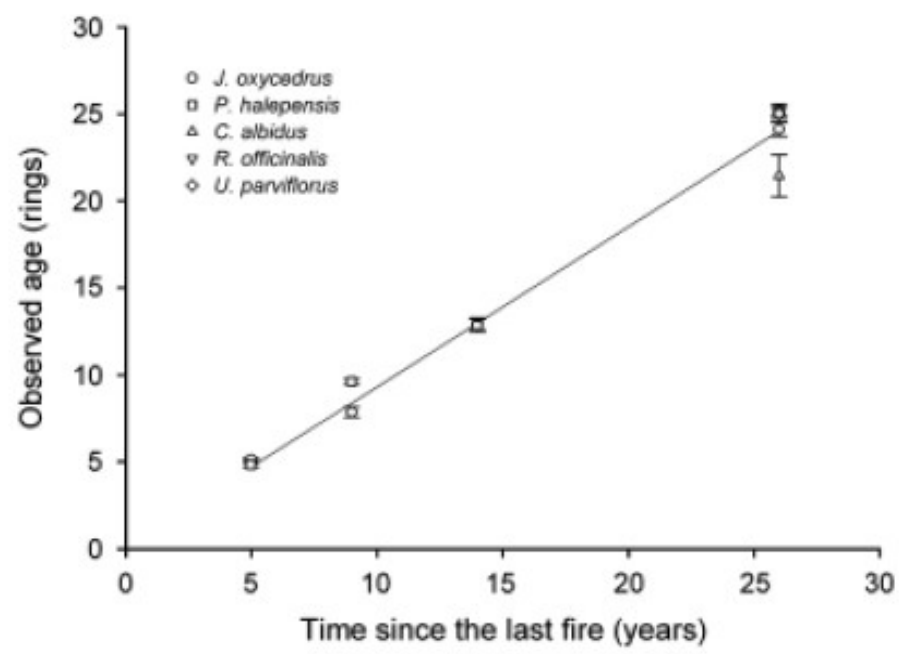

Fig. 1. Relationship between observed age, measured as number of rings in the main stem, and time since the last fire for each stand $\left(r^{2}=0.98 ; P<0.0001 ; n=13\right)$. 




Fig. 2. Dynamics of total standing dead fuel in different stand ages after fire for all study species.



Fig. 3. Values (mean $\pm S D$ ) of total standing dead fuel for individuals of all species in older stands (26 years old). Differences in post-hoc ANOVA are shown with different letters. 


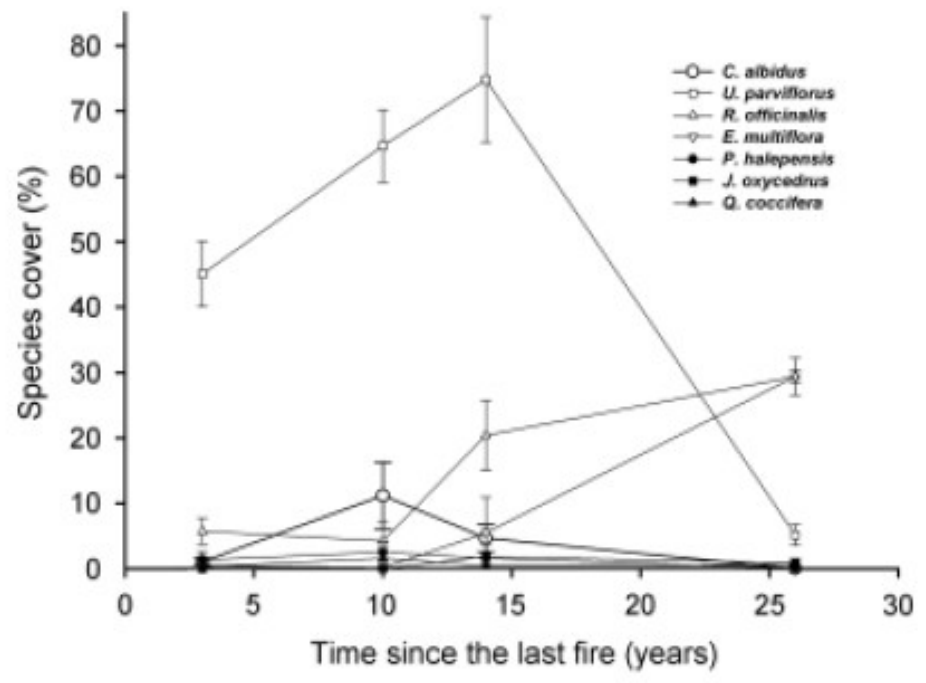

Fig. 4. Changes in specific cover with time since the last fire (years) in Mediterranean gorse shrubland.

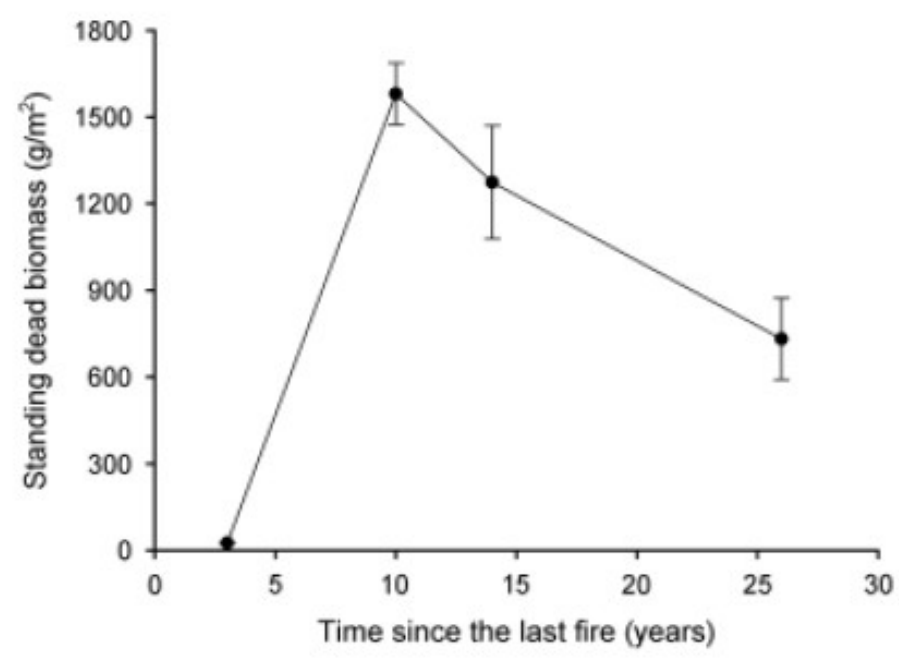

Fig. 5. Dynamics after fire of standing dead biomass accumulated along succession in Mediterranean gorse shrubland. 